\title{
Realismo crítico e desigualdades sociais: considerações a partir de uma pesquisa avaliativa
}

\author{
Critical realism and social inequalities: considerations from \\ an evaluative research
}

Delaine Martins Costa (https://orcid.org/0000-0003-2222-5676) ${ }^{1}$

Rosana Magalhães (https://orcid.org/0000-0003-3831-8877) ${ }^{1}$

${ }^{1}$ Departamento de Ciências Sociais, Programa de Pós-Graduação em Saúde Pública, Escola Nacional de Saúde Pública Sérgio Arouca, Fiocruz. R. Leopoldo Bulhões 1480, Manguinhos. 21041-210 Rio de Janeiro RJ Brasil. delaine.costa@ ensp.fiocruz.br

\begin{abstract}
Based on different theoretical references (public health, program evaluation, and critical realism), the paper analyzes whether conditional cash transfers contribute to the reduction of monetary poverty and improved health care. It employs evaluative research material, consisting of a case study on the health conditionalities of the "Bolsa Familia" Program (PBF) and its implementation by the Family Health Strategy in a primary care service (PHC service) located in a slum area in Rio de Janeiro. Experiences and perceptions of managers, health professionals, and beneficiary families were prioritized to understand the $d y$ namics of the program. A predominant perception is that the PBF "benefits those who need $i t$, but also those who do not need it". On the one hand, health care is recognized as limited, since households are vulnerable and with health problems resulting from this condition. On the other hand, having access to the Clinic is a crucial resource since the benefit is seen as of little value, which reinforces the idea of "aid". It concludes that the three domains of stratified reality contribute to understanding the scope of programs that address the imbrication of biological and social aspects in contexts marked by inequality and poverty.
\end{abstract}

Key words Social inequalities, Poverty, Evaluation, Critical realism, Public health
Resumo A partir de distintos referenciais teóricos (saúde coletiva, avaliação de programas e realismo crítico), o artigo analisa se a transferência de renda condicionada contribui para a redução da pobreza monetária e a melhoria do cuidado à saúde. Utiliza material de pesquisa avaliativa, constituída por um estudo de caso sobre as condicionalidades de saúde do Programa Bolsa Família (PBF) e sua implementação pela Estratégia de Saúde da Família, em uma Unidade Básica de Saúde, localizada em uma favela no Rio de Janeiro. Para compreender a dinâmica do programa, foram priorizadas experiências e percepções de gestores, profissionais de saúde e famílias beneficiárias. Como percepção predominante, destaca-se que o PBF: "beneficia quem precisa, mas também quem não precisa". De um lado, os cuidados em saúde são reconhecidos como limitados, uma vez que as famílias são vulneráveis e apresentam problemas de saúde decorrentes desta condição e, por outro, ter acesso à Clinica é um recurso fundamental dado que benefício é visto como de pequeno valor o que reforça a ideia da "ajuda". Conclui que os três domínios da realidade estratificada contribuem para compreender o alcance dos programas que lidam com a imbricação de aspectos biológicos e sociais em contextos locais marcados pela desigualdade e pobreza.

Palavras-chave Desigualdades sociais, Pobreza, Avaliação, Realismo crítico, Saúde pública 


\section{Introdução}

O artigo apresenta análise parcial dos resultados de pesquisa avaliativa e tem por objetivo identificar possíveis efeitos e limites da transferência de renda condicionada para a redução da pobreza monetária e a melhoria do cuidado à saúde. Utilizou como principal referencial teórico o realismo crítico ${ }^{1}$ e como metodologia o estudo de caso, em uma Unidade Básica de Saúde (UBS), localizada em uma favela no Rio de Janeiro. A pesquisa tomou como referência duas políticas públicas federais: a Política Nacional de Atenção Básica (Portaria no 2.488, de 21 de outubro de 2011) e o Programa Bolsa Família (Medida Provisória no 132 , de 20 de outubro de 2003, transformada na Lei no 10.836, de 9 de janeiro de 2004).

O projeto da Reforma Sanitária e a instalação de um Sistema Único de Saúde (SUS) caminharam pari passu à construção da democracia baseada no princípio de inclusão social e da redução das desigualdades. Passadas três décadas, os desafios da sustentabilidade e institucionalidade do SUS ainda reúnem muitos "nós críticos"2 e, nesse contexto, a Estratégia da Saúde da Família (ESF) se destaca como preponderante para a expansão e o desenvolvimento da atenção básica. Foi também no contexto democrático que mudanças ocorreram no âmbito da institucionalização do modelo socioassistencial, dando origem a um conjunto de normativas e estruturação da política.

A Política Nacional de Assistência Social (PNAS/2004) introduziu mudanças conceituais que implicaram em novas lógicas de gerenciamento, estrutura administrativa e controle das ações. Com a aprovação da Norma Operacional Básica do Sistema Único de Assistência Social (NOB/SUAS, 2005) passou-se a regular e a organizar os elementos essenciais da política. No âmbito do então Ministério do Desenvolvimento Social e Combate à Fome, foi criado o Programa Bolsa Família (PBF) que se constituiu na transferência direta de renda, com condicionalidades, para as famílias pobres e extremamente pobres.

A criação de ambos os Sistemas (SUS e SUAS) impôs uma série de desafios para a consolidação da proteção social e o alcance dos direitos. A pesquisa se insere no debate que perpassa as políticas de transferência de renda em sua interface com a saúde, a intersetorialidade e as desigualdades sociais dada a importância de ampliar investigações que tratem da relação e da interação entre o PBF e a ESF.

Compreende-se que o realismo crítico (entendido como uma abordagem filosófica) se en- trelaça aos estudos sobre avaliação e se constitui em um dos pilares da avaliação baseada na teoria do programa. Considerando que os autores fazem usos diferenciados do realismo crítico, este se mescla aos enfoques da avaliação baseada na teoria cujas questões epistemológicas (que dizem respeito ao conhecimento) se sobrepõem às de cunho ontológico (que dizem respeito ao ser) e colocam em xeque o alcance do conhecimento científico, incluindo-se aí a prática avaliativa, as teorias produzidas sobre a realidade e os programas em saúde.

Utilizando-se do modelo de Bhaskar ${ }^{1}$, acerca das dimensões transitiva (qualquer conhecimento) e intransitiva (que independe do sujeito) do conhecimento, chega-se à concepção de realidade estratificada constituída pelos domínios do real, do atual e do empírico. No artigo, estes foram operacionalizados tendo em vista o contexto específico da pesquisa: as desigualdades sociais, o cuidado à saúde, os programas de transferência de renda condicionada e de saúde da família em um território marcado pela complexidade das experiências. Vale sublinhar que o realismo crítico tout court foi utilizado de maneira não ortodoxa uma vez que a obra Bhaskar se apresenta em "diferentes ondas" $\mathrm{e}$ tem sido adotada nos estudos avaliativos em múltiplas abordagens.

\section{Abordagem teórica}

\section{O real, o atual e o empírico: ontologia das desigualdades e dos programas sociais}

O realismo crítico permite lançar questões e refinar abordagens e estratégias metodológicas sobre a avaliação de programas e intervenções complexas no campo da saúde. No caso da pesquisa avaliativa, uma das principais contribuições refere-se à apreensão dos programas e iniciativas públicas a partir da ontologia acerca do que é o real. A pergunta de cunho ontológico "o que são os programas sociais?" permite diferentes possibilidades de resposta na literatura desde uma posição mais normativa e empirista até aquelas ancoradas no realismo crítico. São estas possibilidades de resposta que interessam para pensar as interseções entre o PBF e a ESF e suas implicações sobre as desigualdades sociais em saúde.

Potvin et al. ${ }^{4}$ fazem uma leitura de Bhaskar que será aqui seguida e complementada com outros autores que se dedicaram ao realismo crítico em relação ao campo da avaliação - como Pawson \& Tilley $^{5}$ que sistematizaram a perspectiva da "avaliação realista" - ou que trouxeram reflexões articuladas à teoria social ou às ciências sociais e 
humanas ${ }^{3}$ para este debate. No artigo são estabelecidas conexões entre esses autores, visando partir do modelo (abstrato) e articulá-lo ao material empírico do estudo de caso.

Parte-se da operacionalização do domínio do atual (entendido aqui como o da ação), no qual se localizam os programas sociais e seus poderes emergentes, os quais provocam as mudanças, e pretende-se ilustrá-los a partir da implementação do PBF e da ESF, no âmbito das condicionalidades de saúde. Explicitados como se concebem os programas (com base na teoria do programa e na teoria da implementação ${ }^{6}$ ) e os mecanismos acionados, descreve-se o contexto complexo em que programas e iniciativas operam e as múltiplas experiências em jogo. Por fim, no domínio do real são selecionados os principais mecanismos sociais e aspectos que incidem sobre as desigualdades sociais, partindo-se do princípio de sua intransitividade.

Ao tratar cada um dos domínios separadamente não significa que estes sejam isolados e não se inter-relacionem. Entende-se que os três domínios operam simultaneamente ainda que não seja possível distingui-los ou percebê-los. Embora o realismo crítico tenha sido utilizado por diferentes autores em pesquisas avaliativas, é importante ressaltar que os conceitos adotados também diferem entre autores, como o de "mecanismo". Bhaskar o utiliza para fazer distinção entre as "estruturas reais" e os "mecanismos gerativos" os quais constituem os objetos intransitivos da teoria científica ${ }^{1}$. Em diálogo com as ciências da natureza, sua teoria acerca da realidade estratificada faz uso tanto do conceito de mecanismos como também de experiência ou experimentos.

A ideia de "mecanismo" não é nova e faz parte do vocabulário das ciências, como um todo. Gorski ${ }^{7}$ dedicou-se ao estudo do conceito de mecanismos sociais, numa perspectiva histórica-comparativa na sociologia, e chega a propor um teoria dos mecanismos causais a partir do realismo crítico. Há uma variedade de acepções do termo que guardam entre si maior ou menor relação com o realismo crítico. Para efeitos da análise, compreendem-se os mecanismos sociais como distintos dos mecanismos naturais ${ }^{7}$, como pertencentes ao domínio do real $^{8}$ e que dispõem de poderes causais emergentes. Ademais, como enfatizado no realismo crítico, a realidade não é tão somente capturada pelos conceitos: é constituída pelos conceitos. O princípio de conceitodependência implica, nesse sentido, numa ontologia do mundo social que varia ao longo do tempo e do espaço ${ }^{7}$.
Em termos de domínios superpostos da realidade, o do empírico pode ser compreendido como o da experiência. Scott, a partir do verbete de Raymond Williams (Keywords, 1976), nos lembra que experiência e experimento eram termos em estreita relação, até meados do início do século XVIII, e que designava como o conhecimento foi alcançado através de testes e observações ${ }^{9}$. Para além das mudanças sócio-históricas acerca do conceito de experiência, importa assinalar que em Bhaskar pode ser entendido tanto em termos de experimentos como também de experiência. Em concordância com a análise de Vandenberghe ${ }^{10}$, Baskhar, em seu segundo livro, adota uma postura da "hermenêutica crítica", a qual trouxe para o primeiro plano a noção de conceito-dependência de agência-estrutura. Segundo o autor ${ }^{10}$, opera, assim, uma mudança de perspectiva que torna a hermenêutica compatível com o realismo crítico. No presente artigo, além destas concepções, também se faz uso daquela formulada por Scott, que recusa a separação entre experiência e linguagem: os sujeitos são constituídos discursivamente sendo a experiência um evento linguístico, porém jamais confinado a uma ordem fixa de significados. Assim, ao invés de naturalizar a experiência tomam-se as categorias de análise como contextuais, contestáveis e contingentes ${ }^{9}$.

\section{Entre as desigualdades sociais e o cuidado em saúde}

Segundo Potvin et al. ${ }^{4}$, com base na perspectiva do realismo crítico de Bhaskar, os programas se situam no domínio dos eventos, dos acontecimentos e, por conseguinte, da ação (domínio do atual) e expressam situações problemáticas. Ao localizar os programas nesse domínio, as autoras destacam três implicações no que concerne à avaliação em saúde: i) a definição do que se constitui um programa; ii) a importância de explorar os mecanismos ativados na resolução de um problema e iii) a relevância da avaliação identificar os mecanismos concretos. É fundamental compreender os programas para além de seu caráter prescritivo e normativo. Um programa é um "objeto em transformação" " constituído por uma "matriz de inter-relações": todos os sujeitos implicados têm a capacidade de exercer poderes causais que podem acionar mecanismos que (re) estruturam relações entre os componentes dos programas.

Torna-se necessário no âmbito dos programas em saúde apreender os "processos por meio dos quais os eventos se transformam”. Mais do 
que conhecer as causas e determinantes de um problema em saúde, cabe explorar como se produz, se reproduz e se transforma um problema ou "quais mecanismos e ações se desenvolvem para que se chegue a um evento problemático" ${ }^{\text {. A ter- }}$ ceira implicação é de ordem metodológica, pois a identificação dos mecanismos concretos não se reduz às percepções que deles têm os sujeitos envolvidos. Como acrescentam: "a teoria torna-se um interessante instrumento de avaliação"4.

Para responder à pergunta o que "são os programas sociais” é importante conhecê-los a partir de múltiplas teorias. Como formulado por Weiss $^{6}$, os programas sociais são empreendimentos complexos que envolvem um vasto conjunto de pessoas, estilos e procedimentos, o que os torna pouco específicos e difícil de descrever o que realmente são. Weiss ${ }^{6}$ acrescenta: "como é esperado que o programa traga mudanças?”.

No caso do PBF e da ESF quais as mudanças pretendidas? Weiss ${ }^{6}$ recomenda que se dedique ao amplo conhecimento dos programas e de seus objetivos - não no sentido de investigar se foram ou não cumpridos e de que maneira - e acrescenta que muitos programas têm múltiplos objetivos. Em meio à sua complexidade e múltiplos alcances, os gestores e os funcionários têm oportunidade para selecionar a parte do programa na qual desejam se concentrar, o que torna relevante identificar quais desses objetivos lhes são reais.

No caso dos programas selecionados, ESF e PBF, são iniciativas complexas com objetivos, contextos históricos e sistemas distintos (SUS e SUAS), que se articulam em aspectos específicos. Uma década de acontecimentos marcantes no país separam a criação dos dois programas e traz desafios analíticos. Os programas aglutinam diferentes narrativas sobre o cuidado à saúde e à pobreza e essa heterogeneidade repercute no processo decisório.

\section{Metodologia}

Para o desenvolvimento da pesquisa, aprovada pelos Comitês de Ética da ENSP e da Secretaria de Saúde/PMRJ, foi privilegiado o estudo de caso, no qual se pretendeu chegar a uma compreensão abrangente sobre a implementação do PBF, a partir de uma Unidade Básica de Saúde (UBS), que atende famílias beneficiárias do Programa. Por razões de sigilo e privacidade, o lugar do estudo de caso e os entrevistados não serão identificados, tal como descrito no Termo de Consentimento. As entrevistas semiestruturadas foram gravadas e, posteriormente, transcritas com recursos do Programa de Programa PósGraduação Stricto Sensu em Saúde Pública, da Escola Nacional de Saúde Pública Sergio Arouca - ENSP, da Fiocruz. Foram entrevistadas 30 pessoas entre profissionais da ESF, da educação, do Centro de Referência de Assistência Social (CRAS), e mulheres titulares do PBF, totalizando 32 horas de depoimentos.

O processo de trabalho se dividiu em três etapas, como sugerido por Minayo et al. ${ }^{11}: 1$ ) exploratória (em 2016 e 2017); 2) trabalho de campo (entre agosto de 2018 e março de 2019); e 3 ) análise e tratamento do material empírico e documental, em execução. A escolha do estudo de caso se fundamenta tanto pelo propósito, quanto pela estratégia de pesquisa. Becker chama atenção que em geral há um duplo propósito: uma compreensão abrangente e o desenvolvimento de declarações teóricas sobre regularidades do processo e estruturas sociais ${ }^{12}$. A compreensão abrangente se fez necessária dada a diversidade de condições sociais em que se encontram os beneficiários do PBF e da ESF no país, o que por sua vez circunscreve especificidades.

O desenho metodológico privilegiou a análise e a interpretação dos dados qualitativos. Os dois momentos são conceitualmente distintos, mas estão imbricados, como indicados por $\operatorname{Patton}^{13}$ : a análise refere-se ao processo de reunir os dados, organizá-los em padrões, categorias e unidades descritivas. Já a interpretação diz respeito à atribuição de significados e significância à análise, explicando os padrões descritivos e sistematizando o padrão das relações e conexões entre as dimensões descritivas. Utilizou como recurso a análise de conteúdo ${ }^{13}$, isto é, a montagem de um sistema classificatório com base em temas e categorias. Fez uso da análise indutiva (temas e categorias de análise que emergem dos dados coletados), de categorias nativas (tal como utilizada pelos participantes) e de tipologias construídas no processo de pesquisa (criadas pelo pesquisador).

Tendo em vista que o referencial utiliza as categorias propostas por Bhaskar, foi empregada a tipologia da ontologia estratificada ao analisar as entrevistas. Sayer ${ }^{14}$, que compartilha desta concepção, assim define-a: o real é o que quer que exista (natural ou social) incluindo-se aí os objetos, suas estruturas e poderes. $\mathrm{O}$ atual (ou factual) refere-se ao que acontece (se e quando estes poderes são ativados) e o empírico diz respeito ao domínio da experiência e pode ser acessado pela observação direta. Sobre o domínio do factual, Hamlin acrescenta: "o que ocorre na reali- 
dade não é necessariamente percebido da forma como ocorre e, contrariamente ao que acreditam os empiricistas, 'ser' não é 'ser percebido'; algo pode existir sem que seja diretamente percebido, apenas inferido a partir dos efeitos que gera"8.

\section{Resultados}

Apesar das mudanças que foram sendo implementadas ao longo do tempo, tanto em termos de gestão quanto na dinâmica das atividades das equipes de trabalho, as percepções sobre a ESF são semelhantes entre os profissionais de saúde, especialmente no que se refere à importância do serviço num território cuja escassez é recorrente e onde a Clínica e seus profissionais representam um acesso a cuidados que via de regra estão para além da saúde. A ESF estimula diferentes mecanismos gerativos da produção de cuidado no âmbito da Atenção Primária em Saúde (controle de diabetes, hipertensão, tuberculose, doenças sexualmente transmissíveis, acompanhamento do pré-natal e pós-parto). Ao mesmo tempo, há a avaliação de que existe um número insuficiente de profissionais, por Equipe de Saúde da Família (EqSF), e que as violências no território são fatores que dificultam o acesso à Clínica e a implementação da ESF. A ausência de profissionais nas equipes, sobretudo médicos, - não prevista na teoria do programa - é recorrente e afeta a rotina de trabalho. Um dos profissionais da Clínica relata sua experiência e outro fala do impacto desta ausência:

A partir de março de 2016 eu fiquei sozinho. Em janeiro de 2017 eu trabalhei com uma médica [...] um mês e meio e depois saiu. E depois eu voltei a ficar mais um período de quase seis meses sozinho de novo. E aí entrou mais uma médica que ficou três meses, depois eu fiquei mais três meses sozinho; depois um outro médico mais três meses, e depois sozinho de novo. Até que eu cheguei agora nesse ponto. Estou trabalhando desde maio, mas pra ser mais preciso, desde o início de junho com a médica da equipe atual, que é a médica de família [...] (E05).

- [É] Horrível. [ficar sem médico.] Porque primeiro, por mais que eu tente reforçar com os ACS, com os agentes comunitários que ficam no acolhimento, que tem coisas que não tem como eu atender, encaminhamento, eu não posso fazer, que antibiótico eu não posso prescrever, enfim. Tem algumas coisas que eles vão colocar barreira porque eles não se sentem, não é responsabilidade deles mesmo mandar embora. Só que a partir do mo- mento que a pessoa entra no seu consultório, ela espera que você dê conta das demandas dela. [...] o que eu tenho que fazer geralmente que é levantar, ir no consultório de alguém, esperar esse alguém terminar a consulta dele, conversar com ele sobre o caso, convencer que a pessoa precisa de alguma demanda médica atendida, esperar que a pessoa ou levante ou fale para mim o que tem que fazer. Aí eu volto, faço o que tem que fazer, levo para a pessoa carimbar e entrego [...]. (E09)

Ainda que a ESF opere com uma concepção ampla e multidisciplinar do cuidado, a medicina adquire centralidade para a implementação da política. Contudo, a prática médica ganha contornos bem definidos dada a formação em medicina de família, ainda que diferentes grupos convivam no âmbito desta especialidade e em torno de uma epistemologia própria, como analisado por Bonet ${ }^{15}$. É possível afirmar que "a capacidade de sentir a vida de uma comunidade"15, que distinguiria a experiência dos médicos de família, se distribui diferenciadamente entre os profissionais da ESF e retorna para a prática (na) clínica entrelaçada aos valores de cada membro das equipes, o que é mais contundente no caso dos Agentes Comunitários de Saúde (ACS).

É possível reconhecer certa regularidade nos depoimentos sobre o que é a ESF e como vem sendo transformada: a complexidade da intervenção; os poderes causais da EqSF; os múltiplos objetivos a serem alcançados e a "seleção" do que é exequível; os elementos contingentes não previstos na teoria; os limites do cuidado para os "casos complexos"; a dificuldade de ações intersetoriais; a necessidade do cumprimento de indicadores e a instabilidade das relações de trabalho. No caso do PBF, há uma maior multiplicidade de percepções e experiências, tanto sobre o significado do Programa quanto sobre sua implementação, especialmente no que se refere às condicionalidades de saúde, podendo, até mesmo, ser afirmado que se trata de um tema controverso.

No contexto estudado, a escassez de serviços prestados pelo poder público e a condição de vulnerabilidade em que se encontra grande parte da população permitem afirmar que o cuidado à saúde foi paulatinamente disseminado pelas EqSF: pelo acesso dos moradores aos consultórios na Clínica, pelas Visitas Domiciliares (VD) realizadas ou ainda pela melhoria dos indicadores epidemiológicos.

A rotina do acompanhamento das condicionalidades do PBF foi incorporada à Clínica a partir de 2012, pois, quando inaugurada, não havia identificação precisa dos usuários beneficiários 
do PBF. Dado que grande parte da população apresenta condições precárias de moradia e renda, os beneficiários do PBF não se destacam de maneira expressiva entre os usuários da Clínica de modo a estimular ações específicas para além das condicionalidades. Como o cuidado à saúde é visto pelos profissionais, que participaram da pesquisa, para além dos cuidados biomédicos, o alcance da ESF abrange direta ou indiretamente os beneficiários do PBF, ainda que ações específicas para o registro do cumprimento das condicionalidades sejam implementadas. O modelo biomédico convive com outras práticas de cuidado ainda que prevaleça, por parte dos usuários, a ideia de cuidado muitas vezes dissociada da prevenção, o que requer um investimento em mudanças de perspectivas sobre esse cuidado. Dado o campo normativo e prescritivo em que as ações de saúde se inserem, as condições sociais dos usuários (beneficiários ou não) impõem outras práticas, no sentido de garantir acesso aos direitos sociais. Os limites do cuidado em saúde são dados não só pela atenção primária per si, mas também pelo reconhecimento que esse cuidado não se esgota no acesso aos serviços de saúde.

A atenção voltada para as "famílias pobres e extremamente pobres", em sua diversidade de configurações, é um aspecto em comum entre os dois Programas. A preocupação em assegurar aos mais pobres uma renda mínima independente de seus proventos não é uma novidade para alguns países europeus. Entre outros, Polanyi ${ }^{16}$ analisou, na Inglaterra, a Speenhamland Law (1795) que, por intermédio de um sistema de abonos subsidiado através de fundos públicos, assegurava ao pobre uma renda mínima independente dos seus proventos. Para Foucault ${ }^{17}$, a Lei dos Pobres introduziu um importante fator na história da medicina social, qual seja a ideia de uma assistência fiscalizada.

Os ACS são acionados e acionam as condicionalidades em saúde do PBF. Para ser um ACS, é necessário residir no território, o que, a princípio, significa conhecer bem sua geografia e população. Em casos como o do RJ, a circulação pelo território só se viabiliza se acompanhada por um ACS. Cabe ao ACS (se desejável) ficar responsável pelas VDs das famílias da área em que reside, o que lhes permite uma maior circulação. As visitas constituem um mecanismo central na ESF, pois viabiliza que o cuidado à saúde seja realizado "extra-muros". Esse é um mecanismo social que permite alcançar aqueles que não vão à Clínica por motivos diversos, como também os que intencionalmente não desejam receber a visita. Por outro lado, as VDs também permitem "mapear" o território, uma vez que identificam os espaços onde vivem famílias mais vulneráveis e, assim, fornecem elementos para planejar e monitorar ações. A VD também é percebida como um momento para melhor conhecer as condições em que vivem as famílias, o que, muitas vezes, não se apresenta numa consulta. As dinâmicas familiares e as condições de moradia são assim problematizadas e a cada visita se torna possível criar e consolidar vínculos entre os usuários do serviço e os profissionais.

As relações de vizinhança podem adquirir outros significados se um ACS conhece e visita as famílias com quem convive e o cuidado em saúde pode ser interpretado como controle e até mesmo falta de privacidade. Há ACS que reconhecem que esta intimidade não lhes agrada ou que acabam ficando disponíveis 24 horas. Em resumo, a VD no território estudado é um mecanismo que tanto acessa o "cuidado" quanto também o "controle" sobre as famílias. No caso das famílias beneficiárias, o binômio cuidado/controle ou "controle sobre o cuidado" traz essa dupla característica o que reforça algumas recusas.

O termo "visita domiciliar" é revelador, pois uma visita pressupõe um convite e, neste caso, há um acordo tácito que um "convite" pode ser acionado a qualquer momento pela EqSF. O convite está implícito na ESF sobretudo em território onde o Estado não "chega". A VD, sob esse aspecto, guia o duplo sentido: tanto o de consentimento (ao convite subentendido na relação), quanto o de recusa (uma vez que não houve de fato um convite). A VD permite que o sentido do cuidado se faça no dia a dia: é o domicílio do idoso acamado que vive sozinho; é a casa que foi construída no "puxadinho do puxadinho" e cujo único acesso é um parapeito do qual o ACS já caiu; é o cômodo do esquizofrênico que vive no andar abaixo da residência familiar e através da janela, com grades, estabelece algum contato externo e recebe comida e água. Outras situações enfrentadas revelam o drama de um diabético em cadeiras de rodas que, em litígio com o irmão, vive sozinho num cômodo, em cima da cama, sem banho e cercado por lixo o que leva os vizinhos a acionarem a EqSF. A ESF também se faz presente no caso da paciente que dorme sobre um colchão na "sala" pois teve sífilis, é soropositivo, está imobilizada por um "derrame" e vive com a filha pequena e alguns membros da família.

Os ACS também passaram a ter controle sobre a segurança no trajeto das casas até a Clínica. Devido à insegurança no território, a EqSF pas- 
sou a adotar o "Acesso Seguro" (uma rede de comunicação oficializada entre os ACS e incorporada à rotina de trabalho que orienta a abertura ou não da Clínica e a circulação pelas micro áreas do território em função dos confrontos armados). Em outras palavras, não é possível (pelo acesso nem sempre fácil) e recomendável (pelo comércio ilícito) transitar pelo território sem a presença do ACS.

As controvérsias sobre o PBF podem ser melhor entendidas se levado em consideração que os ACS são moradores de um território cujas trajetórias de vida se assemelham às dos beneficiários. Fazem parte de famílias que se instalaram décadas atrás ou num período mais recente vindos de outros bairros, favelas ou estados; filhos dessas famílias que foram criados e constituíram outras famílias no mesmo local que os pais, estudaram e viram na Clínica uma oportunidade de trabalho, mesmo sem ter clareza do tipo de serviço, o que era a ESF ou ser um ACS. Somam-se à experiência no território, o acompanhamento dos modos de viver dos beneficiários que não necessariamente usam o recurso exclusivamente para alimentação. Nem todos os beneficiários são julgados como aqueles que realmente necessitam do recurso: isso se passa tanto porque nas próprias famílias dos ACS há casos de pessoas que necessitam e não recebem (e vice-versa), como também daquelas famílias, que em VD ou na Clínica, sabe-se que não recebem o benefício, mas julga-se que é necessário. Ainda que sabedores do alcance errático do PBF, foi uma regularidade identificar que o benefício "ajuda a quem precisa" e mesmo que atenda famílias que "não precisam", o benefício deve permanecer porque seu valor é reconhecido como muito baixo. É facultado ao Programa (especialmente à Assistência Social) a pouca "fiscalização" sobre as famílias para evitar o uso indevido do benefício ou seu acesso para famílias que não vivem em condições de pobreza e extrema pobreza:

As pessoas vêm aqui obrigadas. Você tem que ver como é que é. É porque você não tá aqui todo dia. Você tem que ver como é que é. Tem pessoas que vem, vem pesar e medir. Mas não é isso que a gente quer. A gente quer que ela frequente a Clínica, que ela entre no consultório, que ela passe por uma consulta, que ela fale dos problemas dela. Se for o caso a gente encaminha para um psicólogo. Pra saber se a criança está sendo nutrida ou não. O que que ela faz com o dinheiro. Isso a gente quer saber. (E06)

[...] Mas não é dizer que eu sou contra o Bolsa Família, eu sou contra a política de, parece que você está dando esmola, mas você não dá condições de sair daquilo. Tem que ter condições de sair daquilo [...] Então acabou que está sendo uma moeda de troca muito falha (E08)

Eu acho que o programa Bolsa Família já é o oposto da saúde da família. O programa Bolsa Família é você largar um pouco de dinheiro na mão da pessoa lá e não tem fiscalização do que a pessoa vai fazer com aquele dinheiro, que também não é um dinheiro que não dá para nada. [...] A minha visão é essa. Eu, politicamente falando, eu tenho uma ideia ao contrário disso, porque você vê os políticos recebendo também vários tipos de bolsa de dinheiro público, com vários tipos de nome e o povo não pode ganhar cento e poucos reais? (E13)

Os demais profissionais entrevistados revelam o desenvolvimento de uma "sensibilidade" para o trabalho em saúde voltado à populações vulneráveis. Esses profissionais não necessariamente conheciam o território e para alguns ir trabalhar numa região reconhecida como perigosa foi uma surpresa, mas também um aprendizado que lhes vinculou à Clínica. Se, entre os ACS entrevistados, o PBF pode causar "horror" e a sensação de "babás” dos beneficiários, para os demais a experiência de atender os beneficiários é avaliada positivamente, como a seguir:

Eu já tive muito preconceito com ele, já tive muitas coisas em relação a ele, me chateava muito... no início, então, que eu não entendia tão bem... e aí agora tento melhorar esses meus pensamentos sobre ele, porque eu achava assim "gente, como pode? A pessoa ganha o Bolsa Família e não vem aqui. Ela não trabalha, ela tem que vir aqui”. Ai eu comecei a aprender que não, ela pode trabalhar e ter Bolsa Família, porque dependendo da renda dividido pro tanto de gente, dá pra ter as duas coisas... [...] (E04).

Se há dissensos, entre os profissionais da Clínica, sobre os efeitos do Programa na redução de desigualdades e os limites das ações de acompanhamento para mudanças nos padrões de cuidado em saúde, entre os beneficiários entrevistados majoritariamente há o reconhecimento de que o benefício "ajuda”, ainda que não seja suficiente. É sobre estes que os mecanismos gerativos de reprodução das desigualdades são os mais sentidos e identificáveis nas trajetórias e experiência de vida. Esses mecanismos gerativos de reprodução operam a partir das dinâmicas de gênero (“os beneficiários” representam uma população quase que exclusivamente feminina), de raça e de classe; do colonialismo (entendido aqui a partir da teoria decolonial ${ }^{18}$ ) e do próprio capitalismo ${ }^{19}$, se é que é possível separá-las. As titulares do benefício entrevistadas expressam a experiência de 
viver em território onde a violência contribui para o isolamento e as oportunidades de inserção no mercado de trabalho formal são raras, cabendo ao cuidado com a família um dos principais projetos de vida. Grande parte reconhece a importância do benefício: porque complementa a renda da família ou porque é a única fonte de renda regular. $\mathrm{O}$ cuidado à saúde se materializa no cotidiano da Clínica e não só no cumprimento das condicionalidades.

\section{Considerações finais}

Ao adotar o realismo crítico, conclui-se que os cuidados em saúde, oferecidos no âmbito das condicionalidades, são reconhecidos como limitados, uma vez que as famílias - em suas multiplicidades de configurações - inserem-se em contextos sociais de relações vulnerabilizadas. Nesse contexto, apresentam condições de saúde decorrentes desta situação: moradia precária e sem saneamento; baixa escolaridade; renda ine- xistente ou insuficiente; sobrecarga das mulheres, em geral jovens e negras; manutenção dos ciclos intergeracionais de pobreza. Apesar do dissenso sobre o alcance do benefício para as famílias, é reconhecida a necessidade da transferência de renda como um mecanismo social necessário para a melhoria das condições de vida, uma vez que viabiliza o acesso a serviços (educação, saúde e assistência) e mercadorias. A clínica e a ESF são percebidas como um recurso fundamental dado que o benefício é visto como de pequeno valor, mesmo entre os mais pobres, o que reforça a idéia da "ajuda".

Conclui-se que os três domínios da realidade estratificada contribuem para compreender o alcance dos programas: as experiências em conceber o que é a saúde de maneira não dissociada entre o biológico e o social; os programas que geram ações e mudanças, tais como o PBF e a ESF, e as estruturas invisíveis e em constante movimento que incidem sobre a permanência e o aumento das desigualdades, especialmente junto a determinados grupos sociais.

\section{Colaboradores}

DM Costa e R Magalhães contribuíram substancialmente para a concepção e o planejamento ou para a análise e a interpretação dos dados; contribuíram significativamente na elaboração do rascunho ou revisão crítica do conteúdo; e participaram da aprovação da versão final do manuscrito.

\section{Agradecimentos}

Agradecemos a Frédéric Vandenberghe (Instituto de Filosofia e Ciências Sociais, da Universidade Federal do Rio de Janeiro) pela leitura e comentários à versão original. 


\section{Referências}

1. Bhaskar R. Philosophy and scientific realism. In: Bhaskar R, Archer M, Collier A, Lawson T, Norrie A, editors. Critical realism: essential readings. London; New York: Routledge; 1998. p. 16-47.

2. Paim JS, Teixeira CF. Configuração institucional e gestão do Sistema Único de Saúde: problemas e desafios. Cien Saude Colet 2007; 12(Supl.):1819-1829.

3. Vandenberghe F. What's critical about critical realism? Essays in reconstructive social theory. London, New York: Routledge; 2014.

4. Potvin L, Gendron S, Bilodeau A. Três posturas ontológicas concernentes à natureza dos programas de saúde: implicações para a avalição. In: Bosi MLM, Mercado FJ, organizadores. Avaliação qualitativa de programas de saúde: enfoques emergentes. $3^{\text {a }}$ ed. Petrópolis: Vozes; 2013. p. 65-86.

5. Pawson R, Tilley N. Realistic evaluation. London, Calif; Thousand Oaks, Sage; 1997.

6. Weiss CH. Understanding the program. Upper Saddle River: Prentice Hall; 1998.

7. Gorski P. Social "mechanisms" and comparative-historical sociology: a critical realist proposal. In: Hedström P, Wittrock B, editors. Frontiers of Sociology. Annals of the International Institute of Sociology: II. Leiden: Brill NV; 2009.

8. Hamlin CL. Realismo crítico. In: Sell C, Martins CB, organizadores. Teoria sociológica contemporânea: autores e perspectivas. São Paulo: Annablume; 2017. p. 48-74.

9. Scott JW. The evidence of experience. Evid Exp 1991; 17(4):773-797.

10. Vandenberghe F. The normative foundations of critical realism. A comment on Dave Elder-Vass and Leigh Price. Journal of Critical Realism 2019; 18(3):319-336.

11. Minayo MCS, Deslandes SF, Gomes R. Pesquisa social: teoria, método e criatividade. Petrópolis: Vozes; 2013.
12. Becker HS. Métodos de pesquisa em ciências sociais. São Paulo: Hucitec; 1999.

13. Patton MQ. Analysing and interpreting qualitative data. In: Patton MQ. How to use qualitative methods in evaluation. Newbury Park: Sage Publications; 1987. p. 144-164.

14. Sayer A. Características chave do realismo crítico na prática: um breve resumo. Estud Sociol 2014; 2(6):732.

15. Bonet O. Os médicos da pessoa: um olhar antropológico sobre a medicina de família no Brasil e na Argentina. Rio de Janeiro: 7 Letras; 2014.

16. Polanyi K. A grande transformação: as origens de nossa época. Rio de Janeiro, RJ: Campus; 1980.

17. Foucault M. Historia de la medicalización. In: Varela J, Alvarez-Uría F, organizadores. La vida de los hombres infames. La Plata: Ediciones Altamira; 1996. p. 85-105.

18. Miglhievich-Ribeiro A. Pós-colonialismo. In: Sell C, Martins CB, organizadores. Teoria sociológica contemporânea: autores e perspectivas. São Paulo: Annablume; 2017. p. 449-474.

19. Federici S. Calibã e a bruxa: mulheres, corpo e acumulação primitiva. São Paulo: Elefante; 2017.

Artigo apresentado em 30/05/2019

Aprovado em 07/08/2019

Versão final apresentada em 14/11/2019 
